A Short Guide to Community Based Participatory Action Research

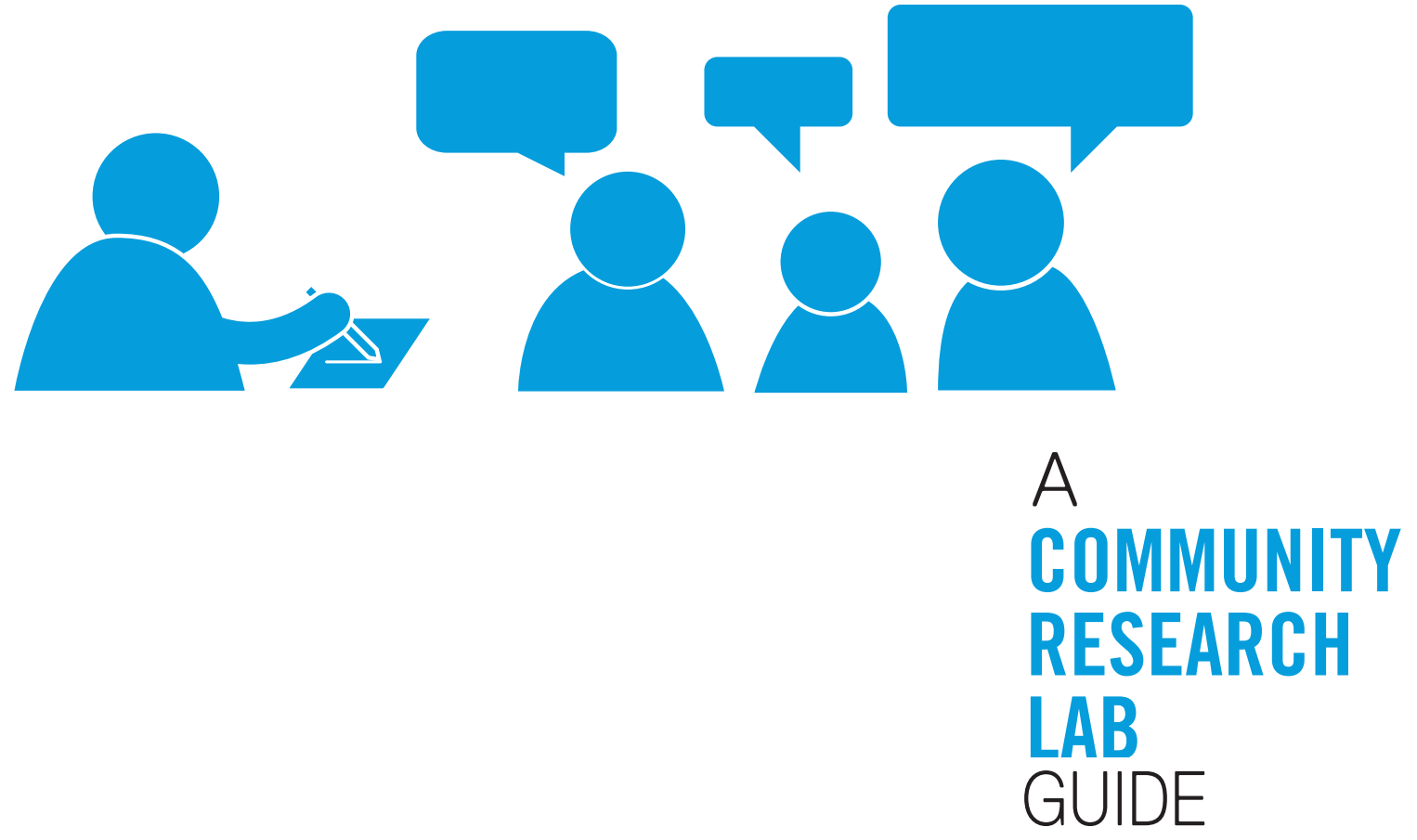




\section{About Us}

\section{Acknowledgments}

\section{ADVANCEMENT PROJECT}

Advancement Project (www.advancementprojectca.org) is a public policy change organization rooted in the civil rights movement. We engineer large-scale systems change to remedy inequality, expand opportunity and open paths to upward mobility. Our goal is that members of all communities have the safety, opportunity and health they need to thrive. Advancement Project's Programs include: Educational Equity, Equity in Public Funds, Healthy City, and Urban Peace Institute.

\section{HEALTHY CITY}

Healthy City (www.healthycity.org) is an information + action resource that unites community voices, rigorous research and innovative technologies to solve the root causes of social inequity. We transform how people access and use information about their communities. As a program of Healthy City, the Community Research Lab partners with community-based organizations to develop, implement, and disseminate data/ mapping projects, tools, and workshops that promote community knowledge and Community Based Participatory Action Research.
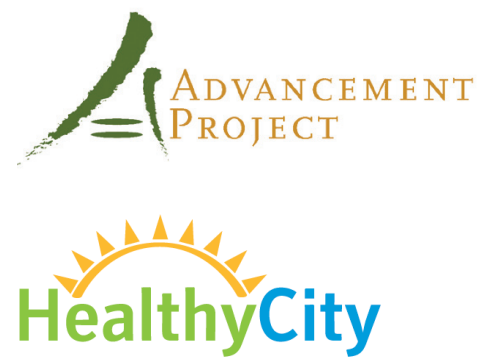

\section{ACKNOWLEDGMENTS}

Healthy City, through the Community Research Lab, developed this guide with funding from First 5 Los Angeles. This and other toolkits can be accessed through the Healthy City website at www.healthycity.org/toolbox.

\section{CONTENT}

Authors: Janice C. Burns, M.A.; Deanna Y. Cooke, Ph.D.; Christine Schweidler, M.P.H.

Editors: Taisha Bonilla, M.T.S. and Tahirah Farris, A.I.C.P, M.PL

\section{DESIGN}

Rosten Woo and Colleen Corcoran / bycommittee.net

For more information, visit www.advancementprojectca.org or contact us at (213) 989-1300.

Copyright Dec. 2011 Advancement Project - Healthy City

All rights reserved. Use and reproduction of these materials in any format should be credited to Advancement Project- Healthy City Community Research Lab. Materials are not to be used or sold for commercial purposes or profit. 


\section{About the Toolbox}

Healthy City supports communities in identifying, organizing, and sharing its collective voice with decision makers at the local and state levels. Through the Community Research Lab, we share best practices and methods for Community-Based Organizations (CBOs) interested in supporting their strategies with research that combines community knowledge with Healthy City technology. Toward this aim, we have developed the Community Research Lab Toolbox.

The toolbox presents research concepts, methods, and tools through topical guides and toolkits such as Community Research, Participatory Asset Mapping, and a Short Guide to CBPAR (all of which can be accessed at www.healthycity.org/toolbox). It is based on best practices from our work with $\mathrm{CBO}$ s and a unique approach to the Community Based Participatory Action Research (CBPAR) framework, which promotes research that:

1. Starts with issues and strategies then produces analysis that informs action

2. Uses mapping technology to engage organizations in the research process

3. Is both community-based and place-based, often focusing on a geographic place such as a neighborhood

The toolbox's CBPAR framework explicitly focuses on community-based organizations that bring together community members to visualize and actualize research and its outcomes. This includes non-profit organizations that operate in specific, local communities and are staffed by, work with, represent, assist, and/or advocate on behalf of residents of those communities on issues that affect their quality of life. These organizations have worked to gain trust among community members and have brought together a spectrum of people with varying ideas and perspectives that unite around a particular set of concerns relevant to a large portion of the community. Though it may have utility for other groups, it supports these organizations whose work directly engages community members in creating change.

\section{About this Guide}

\section{How can this guide be used?}

+ As an Introduction to the CBPAR framework, which democratizes how research is conducted in communities and guides the research methods covered in all of the Community Research Lab toolkits

+ As a workbook for workshops on understanding how to apply the CBPAR framework to research that is place-based and informs social action.

+ As a resource and information guide for conducting research within the CBPAR framework.

\section{What will you find in this guide?}

+ Key research concepts and methods

+ Glossary terms in BOLD

+ Notes like the one below to write down any thoughts or ideas you have as you read

HOW CAN THIS GUIDE BE USEFUL IN YOUR SPECIFIC WORK OR PROJECTS?

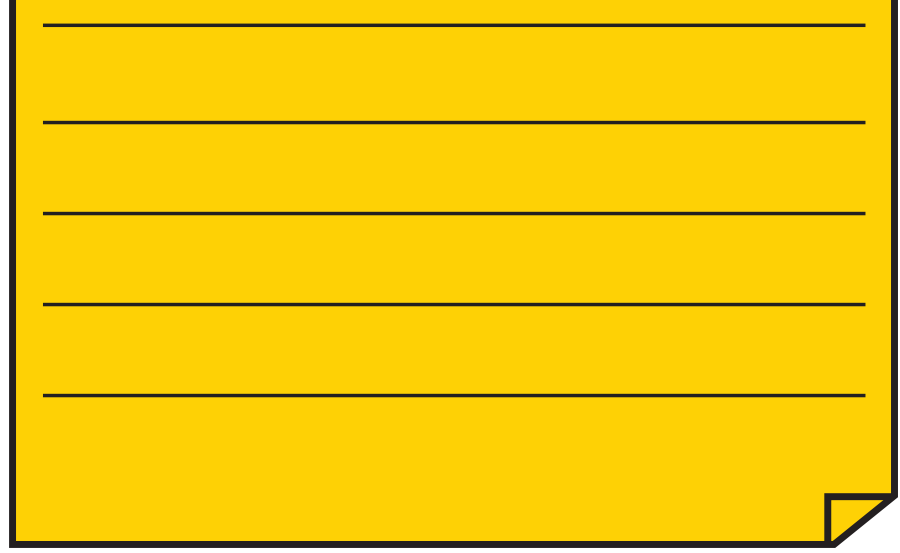


I. WHAT IS COMMUNITY BASED PARTICIPATORY ACTION RESEARCH? $\mathbf{5}$

I. CBPAR AND PLACE-BASED RESEARCH

III. COMMUNITY PARTICIPATION AND ENGAGEMENT

IV. BENEFITS OF CBPAR

V. RESEARCH ETHICS IN CBPAR

VI. PLANNING A CBPAR PROJECT 10

VII. GLOSSARY

VIII. RESOURCES AND REFERENCES 
This page left intentionally blank. 


\section{What is Community Based Participatory Action Research?}

Community Based Participatory Action Research (CBPAR) is a collaborative approach to research that involves all stakeholders throughout the research process, from establishing the research question, to developing data collection tools, to analysis and dissemination of findings. It is a research framework that aims to address the practical concerns of people in a community and fundamentally changes the roles of researcher and who is being researched. The CBPAR framework begins with a community's issue, proposed action, or strategy and then supports or enhances this action with research that is community based and engaged. 'It frames research to be:

COMMUNITY BASED - grounded in the needs, issues, concerns, and strategies of communities and the community-based organizations that serve them

PARTICIPATORY — directly engaging communities and community knowledge in the research process and its outcomes

ACTION BASED AND ORIENTED-supporting and/or enhancing the strategic action that leads to community transformation and social change

By its nature, CBPAR is applied research; it seeks to change issues that are critical to communities and focuses on engaging community members in research directed at addressing their social concerns. It is derived from several research approaches that are based on communities collaborating with researchers (ex. Community Based Research), or community members engaging in all aspects of the research process (ex. Participatory Action Research, or Action Research). As a framework for research conducted in, for, and by communities, CBPAR recognizes that:

+ Community knowledge is irreplaceable and provides key insights that ground-truths administrative data

+ Complex social issues often cannot be well understood or resolved by "expert" research

+ Interventions from outside of the community have often had disappointing results

+ Communities should have equal inclusion and collaboration in the identification, research, and resolution of community issues

+ There is value and legitimacy in the knowledge of individuals, families, and others in the community

CBPAR has a specific goal of collaborative research that engages stakeholders in an iterative research and action process. The diagram below shows that CBPAR links research and action, recognizing that social action requires further research and social research requires further action."
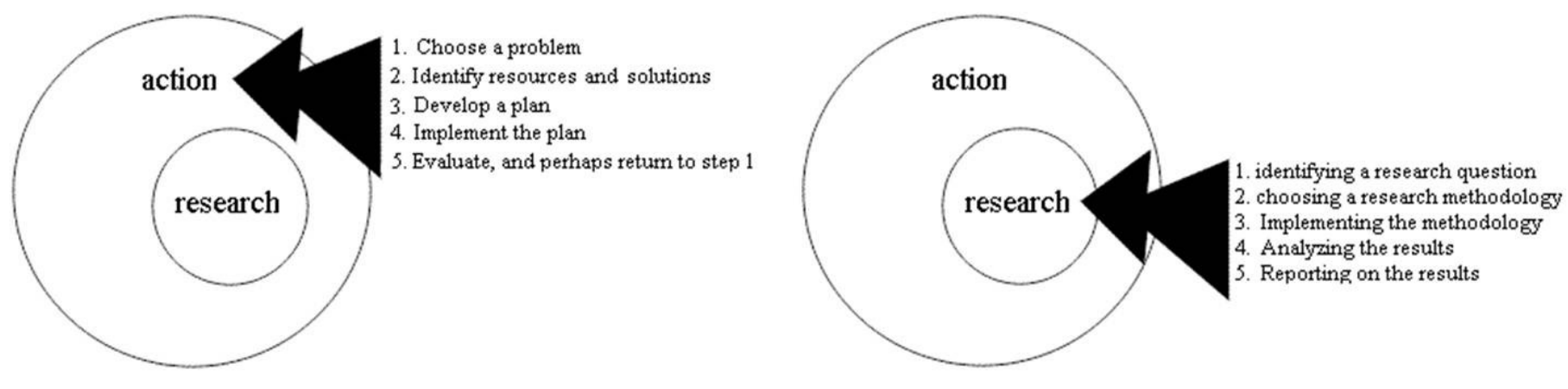


\section{CBPAR and Place-Based Research}

Often, the work of CBOs centers on a specific geographic community that can be defined by the streets, landmarks, or other physical boundaries. Therefore, the CBPAR framework discussed in this guide promotes community research that focuses on a geographic place or neighborhood. It recognizes that CBOs often refer to community as a place, or a physical, geographic space or location, such as a neighborhood, in which issues and interventions are concentrated and change is intended to occur. This framework serves as a foundation to community research that is community-based (engages the community) and place-based (focuses on a geographic area).

The work of $\mathrm{CBO}$ includes place-based strategies that build upon the existing strengths and address the multiple issues of the places they work in. Building upon this holistic model of neighborhood change, place-based research, within the CBPAR framework, uses comprehensive, multi-sectored, asset-based, long-term, collaborative, innovative, and analytical research methods. It "aims to apply methods of data collection and analysis to generate findings that have highly practical results. The audience for such findings is typically made up of community members, practitioners, and local policymakers who wish to design an intervention that benefits a geography-...based community." iii

Like CBPAR, place-based research recognizes that residents have the ultimate knowledge of the issues, strengths, and solutions that most impact their community. It thrives with community engagement in the research process, especially through primary data collection methods such as interviews, focus groups, and Community-Engaged Mapping. This community engagement ensures that those who represent that place, particularly those who reside there, ground this research with their unique perspectives and experiences.

WHAT PLACE DOES YOUR PROJECT/ISSUE FOCUS ON?

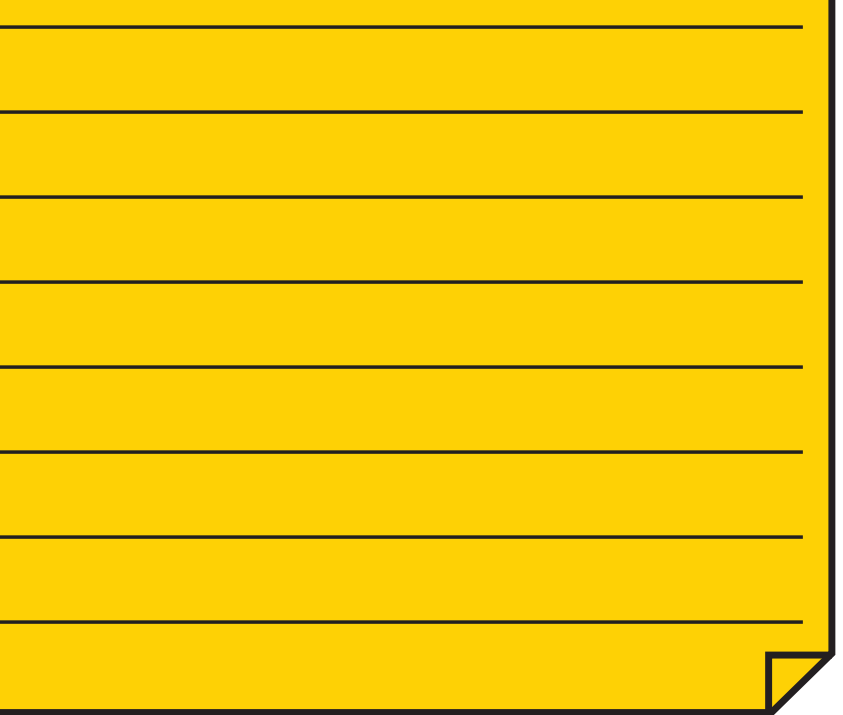




\section{Community Participation and Engagement}

The core principles and values of the CBPAR framework ensure that community members participate in the research and developing outcomes that they can use to make changes in their own communities. It requires a high level of contact and interaction between researchers and the community to engage "in a time-intensive process of collaboration over research design, implementation, and analysis." iv Whether through interviews, focus groups, or other research methods, the involvement of community members in the research process checks and balances the research to challenge and, therefore, strengthen its accuracy and validity.

As displayed below, participation falls along a continuumfrom community members having minimal input and the focus primarily on gaining community responses, to community members engaging in developing research tools and processes, to community members engaging in all aspects of the research, from the design phase, through data collection, data analysis, dissemination and action.

The distinction can also be thought of as a continuum defining a "Researcher," in relation to a community being researched. Traditionally, a researcher is thought of as a trained scholar; perhaps someone with a Master's degree or Ph.D., who may or may not be a member of the community, and may or may not share the specific goals, concerns or perspectives of the community. Often, the traditional view of a researcher is that they want to collect information from communities, but do not necessarily want to get to know the communities personally or provide a report of the information that they collect. As you move across the continuum (towards more participatory research), the distinction between researcher and community begins to shift. Community members may be involved in creating the research questions. The researcher may then collect and analyze the data themselves, interacting very little with the community.

At the end of the participation continuum, community members will be in control of all aspects of the research. The community is creates the research questions, collects and analyzes the data, and interprets the findings to identify solutions. In the CBPAR framework, more participation is better.

HOW DO YOU INVOLVE YOUR COMMUNITY IN RESEARCH? WHERE DO THEY FALL ON THE CONTINUUM BELOW?

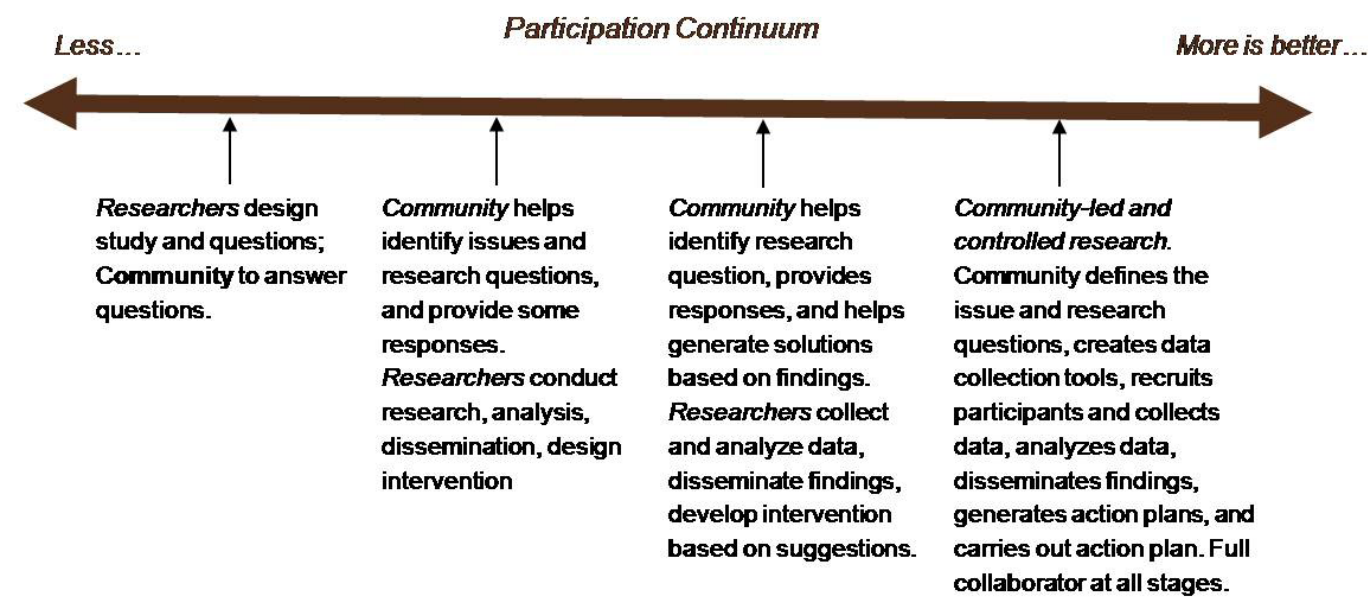




\section{Benefits of CBPAR}

There are critical benefits of CBPAR compared to traditional research. Communities who use CBPAR as a framework for research are able to: ${ }^{v}$

+ Facilitate collaborative, equitable partnerships in all phases of research

+ Balance research and action for the benefit of all

+ Recognize community as unit of analysis

+ Build on community strengths and resources (assets)

+ Promote joint learning, skill-sharing and capacitybuilding among all partners

+ Engage in a long-term process and commitment
+ Emphasize and engage in addressing the often complex causes of local problems

+ Disseminate findings and knowledge gained to all partners and involves partners in the process of taking action or next steps

+ Involve systems development through a cyclical and iterative process

With community participation being such a critical component of the CBPAR framework, it carries its own list of benefits during the research process and in its outcomes, as shown in the table below.

\begin{tabular}{|l|l|}
\hline Community Participation in... & Results in... \\
\hline Identifying issues & $\begin{array}{l}\text { increased alignment with critical issues experienced } \\
\text { from the community, empowers communities to take } \\
\text { action and provides motivation to participate in process }\end{array}$ \\
\hline $\begin{array}{l}\text { Development of study design and } \\
\text { proposal submission }\end{array}$ & $\begin{array}{l}\text { increased acceptability of study approach by } \\
\text { stakeholders, possibility of funds for community }\end{array}$ \\
\hline $\begin{array}{l}\text { Planning and/or carrying out } \\
\text { recruitment and retention of } \\
\text { participation }\end{array}$ & enhanced recruitment and retention \\
\hline $\begin{array}{l}\text { Development of data collection } \\
\text { tools and testing }\end{array}$ & $\begin{array}{l}\text { increased reliability of results; helps identify and better } \\
\text { cope with potentially sensitive issues and situations, }\end{array}$ \\
\hline $\begin{array}{l}\text { Development and implementation } \\
\text { of action plan }\end{array}$ & $\begin{array}{l}\text { greater cultural and social relevance to the population of } \\
\text { the community, increased likelihood of bringing about } \\
\text { lasting positive change }\end{array}$ \\
\hline $\begin{array}{l}\text { Analysis, interpretation, translation } \\
\text { and dissemination of findings }\end{array}$ & $\begin{array}{l}\text { increased validation of results, enhancement of } \\
\text { translating findings into action }\end{array}$ \\
\hline
\end{tabular}




\section{Research Ethics in CBPAR}

Research Ethics are the principles and rules that guide how people should be treated, when they are participants in a research process or project. It might be difficult to anticipate all of the ethical dilemmas that may arise during a Community Based Participatory Action Research project, but it is important to be sensitive to the people involved in your research. Here are some ethics to consider:

ACCESSIBILITY OF FINDINGS. Are the findings presented in ways that community members can understand, access, or find meaningful?

BENEFITS TO THE PARTICIPANTS. How will you ensure that the participants in the community are not harmed during the research and gain as much benefit as possible through their participation?

COMMUNITY VOICE. Who is the community? Who represents the community? Who speaks for the community? Do participants come from only some of the areas you are working in? Do they represent only some of the social identities in the community overall? Are there institutional, organizational or other social dynamics that privilege some voices over others? Will some portions of the community benefit more than others as a result?

CREDIT. How are the results represented? Whose voice(s) are heard and represented? Who receives credit for the work conducted?

DATA OWNERSHIP. Once the data has been collected, who owns it? Where is it stored? How will you responsibly make the data available to the different community and other stakeholders?

DIVISION OF LABOR. How does equity translate into divisions of labor on the project/process? Is the work divided equitably among partners?

JUSTICE. Do all members of the community have equal opportunity to participate in the research? Are there some participants who are unfairly impacted by the research?
(Ex. The U.S. Public Health Service Syphilis Study at Tuskegee included only poor African American men, who were not treated for the disease even when a cure was found; the study was also conducted without the benefit of their informed consent. For details about this study, visit http://www.cdc.gov/tuskegee/index.htm/).

PRIVACY. Will it do any harm to the community or individuals to report the findings? How can you protect privacy in the data collection and sharing process? Did you get adequate permission from participants or those that represent them (for example, parents/guardians of minors)? Do they understand and agree with the way you plan to use the data/information?

\section{REPRESENTATION OF LOCAL COMMUNITIES.}

Does the presentation (or presenter) of findings in any way reinforce negative social stereotypes in presenting communities? Be mindful and transparent about how representative the findings may or may not be of the community based on participation.

RESPECT. How do you maintain respect for a person's ability to engage or not engage in the research without coercion or force?

RIGOR OF RESEARCH AND FIDELITY TO FINDINGS. Are the findings being presented accurately? Are they presented with any bias or in a way to make people hear what they want to hear?

If you are conducting research that involves community members and this research will be published, you may want to consider an ethical review board. For more information on this topic, see the University of Southern California's Office for the Protection of Research Subjects brochure "Is Your Project Human Subjects Research?"at www.usc. edu/admin/provost/oprs/training/brochures.html. 


\section{Planning a CBPAR Project}

Planning every CBPAR project is a unique process. It can be time-intensive, including research design, implementation, and analysis. It can involve community members, community-based organizations, researchers, as well as individuals who may represent all of these categories. ${ }^{\text {vi }}$ Below are some tips, with steps and suggestions to take into consideration when planning a CBPAR Project.

\section{Initial Considerations}

STAFF-What time does your staff and organization have to commit to the research project? What is the staff's capacity to conduct or train others to conduct research?

MONEY - How much might this project cost? Is there funding to cover these costs? Can you incur the costs, apply for funding, or work creatively with partners to share costs?

DATA - Do you have data or access to the data that you will need for your project? What will you do with it once the project is done?

EQUIPMENT AND TOOLS-Are there any specific equipment or tools needed, such as technology or software to collect and analyze data (ex: GIS)? If so, do you have them?

PARTNERSHIPS AND COLLABORATION-If your organization does not have access to some of the above resources, is there an organization that does who you may partner with?

EXPERTISE-Can your organization plan a project that lends itself to the research expertise of your staff, or partner with others who have specific expertise?
Once you have made these considerations and decide to proceed with the project, you can use the process model outlined on the following pages as a guide to implementing your project. Each step includes a list of questions to ask as you proceed with the research process. It mirrors steps in the action research diagrams and adds the important step of partnership engagement. Since this research model reflects a collaborative research process that can be as time and labor intensive as the action, partnering with other organizations can provide critical sharing of resources.

WHICH OF THESE WOULD BE STRENGTHS/ CHALLENGES IN PLANNING YOUR PROJECT?

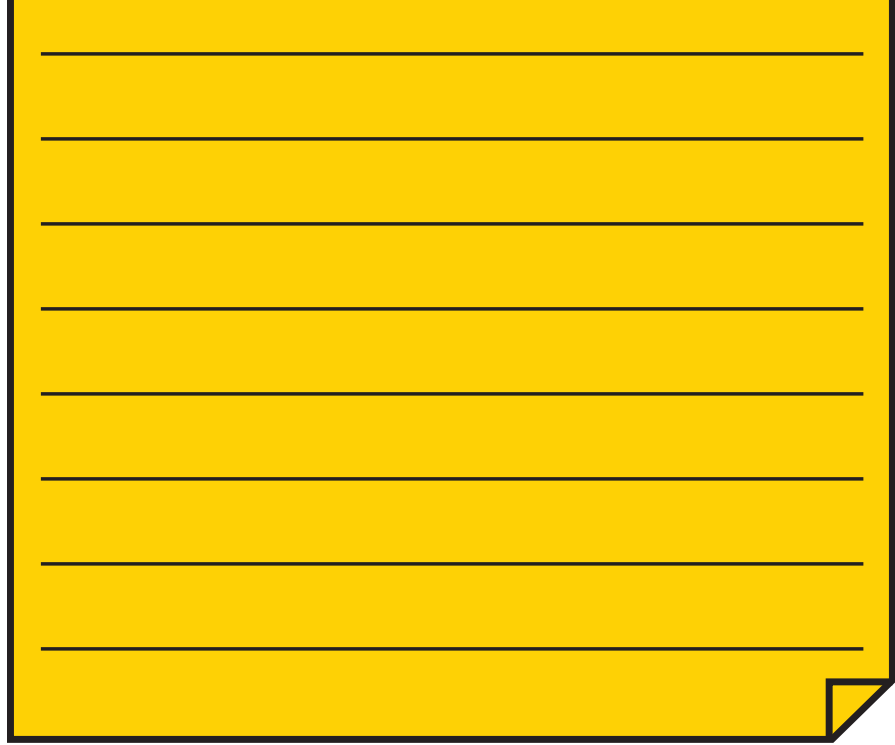


COMMUNITY BASED PARTICIPATORY ACTION RESEARCH PROCESS MODEL

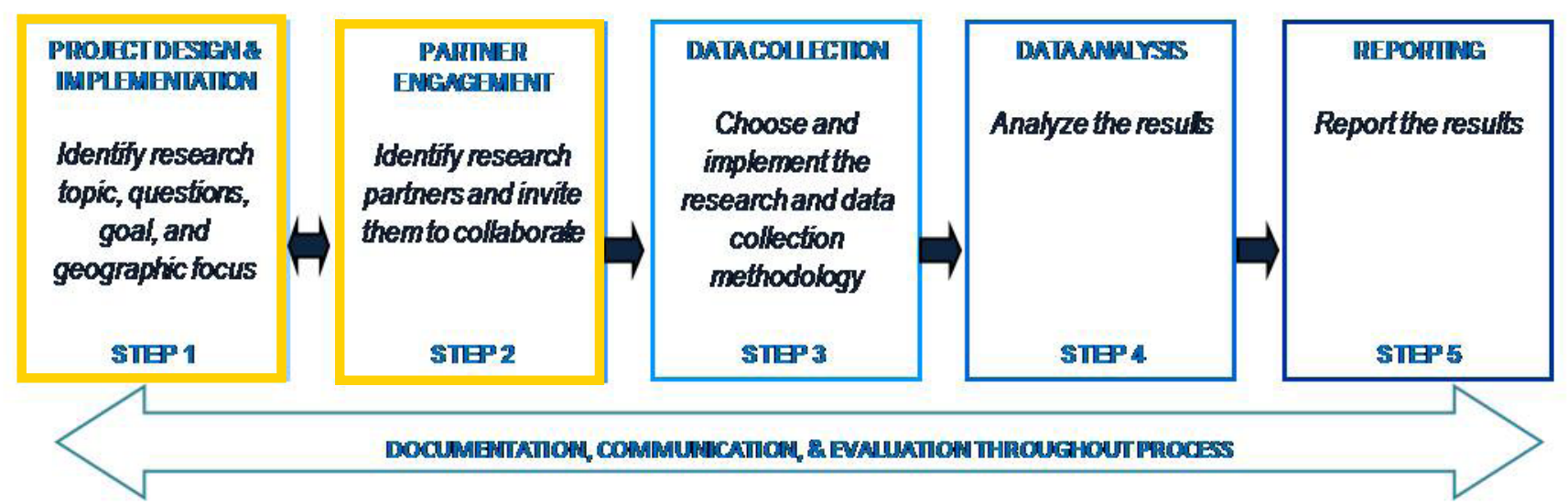

\section{Step 1: Project Design and Implementation \\ (in some cases, may occur after \\ Engagement)}

OBJECTIVE: Identify your research question and geographic focus

+ Based on community need, strengths, interests, mission and capacity to take action, what is the general issue you are addressing?

+ What is the specific problem/issue?

+ What are the research questions you would like to answer?

+ What do you want to know? What hypothesis do you want to test? What do you want to highlight or draw attention to that is not already known, or if known, not sufficiently demonstrated?

+ What can you feasibly act upon?

+ What are the rough geographic boundaries where you would like to engage participants and take action? The 'community' may not agree with your definition of the community boundaries, so consider building in time to discuss and adjust these boundaries.
Step 2: Partner Engagement (in some cases, may occur before Project Design)

OBJECTIVE: Identify action research partners and invite them to collaborate

+ Based on the general issue and geography - who are the key stakeholders?

+ Of these, who will you collaborate with? If you already have a collaborative, consider conducting a stakeholder analysis to see who might still be missing.

+ Will this group address the different constituents of the community?

+ What is the level of participation in the different elements of the process?

+ Will you design the research with some of your constituents?

+ How much of the process will project partners participate in?

- Clarify each participant's expectations of the process, and in what way each person or group wants to contribute: What is their interest and why? What resources do they have available? 
COMMUNITY BASED PARTICIPATORY ACTION RESEARCH PROCESS MODEL

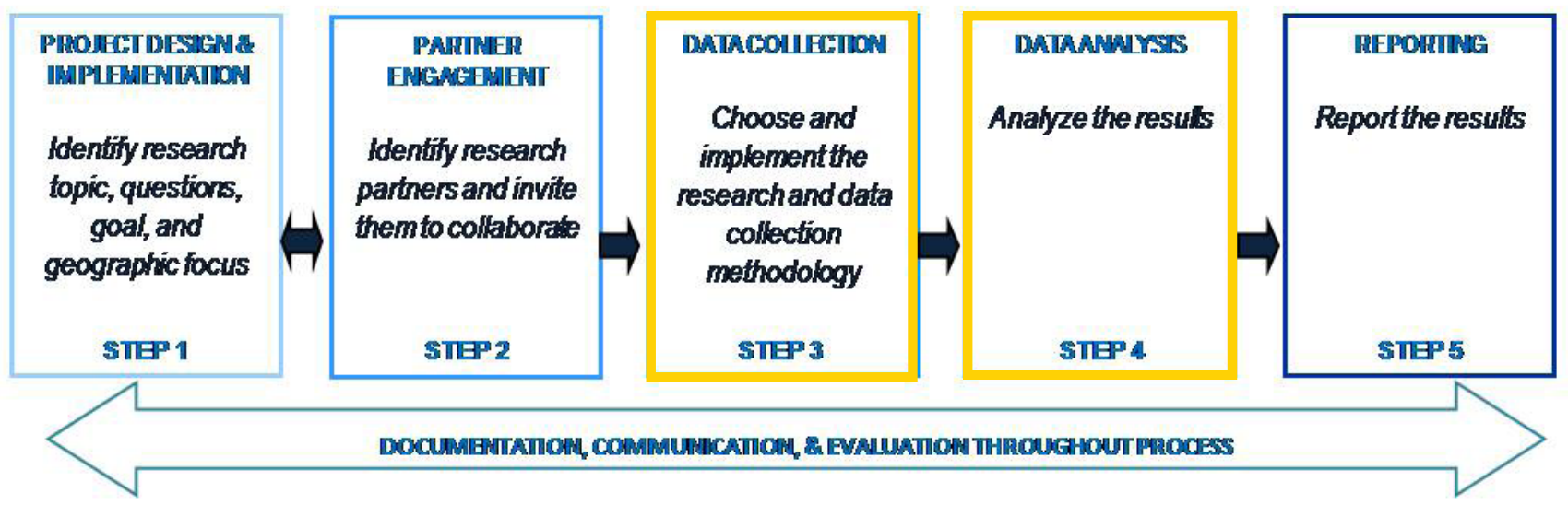

\section{Step 3: Data Collection}

OBJECTIVE: Refine research questions, choose and implement data collection methods, and identify key participants

+ Based on the issue and participants, do you need to refine or change your specific research questions?

+ Who will you collect data from? Who has specific knowledge of the topic?

+ How many participants will you have? What is a good sample size to be representative?

+ What is your capacity to engage participants?

+ How do you anticipate using the findings?

+ Who will be your target audience for the research findings?

+ What specific data do you need to answer this question? Maybe a combination of community knowledge and administrative data? (Ex. perception of safety compared with crime statistics)

- What is already available? What can you collect?

- Test your assumptions! Will the data you collect both answer your research question and provide you a way to take action?

\section{Step 4: Data Analysis}

OBJECTIVE: Create and implement a plan for analysis

+ Develop data collection tools based on the format you would like to use to address your research question.

+ It is important to understand the geographic component of your data - do you need addresses? Zip codes?

+ Will you use web-based tools? (Ex. HealthyCity.org)

+ Will you need to create original forms?

+ Determine the best participation format

+ Will you collect this data in person? What format? (Ex. group discussion)

+ Do you have interests beyond data collection (organizing, advocacy, etc.)?

+ Prepare and test web-based and other tools for data collection

+ Develop plan for analysis

+ What is your format for analysis? (Ex. maps)

- What basic information will the data provide? 
COMMUNITY BASED PARTICIPATORY ACTION RESEARCH PROCESS MODEL

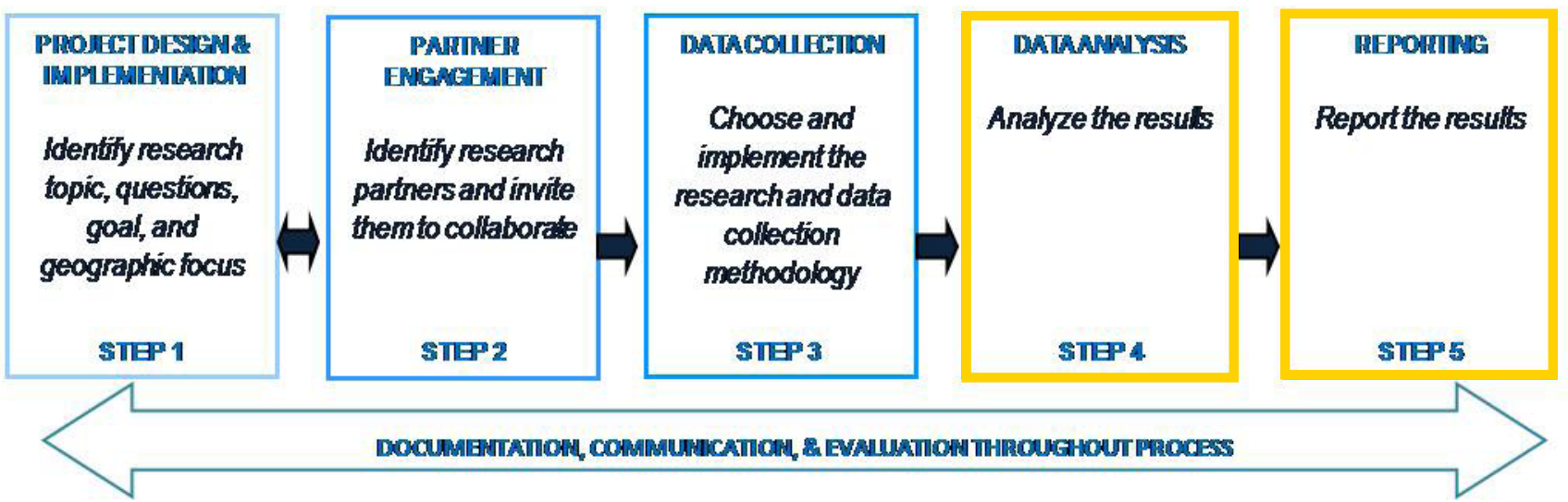

- What do you expect to learn about your specific issue from the analysis?

- How will you look for clear patterns, any highs or lows?

- How will the data/analysis address your research question?

+ What information might you anticipate that the research will not provide and that you would need to investigate further?

\section{Step 5: Reporting}

OBJECTIVE: Analysis, Dissemination, and Action!

+ Develop plan for presenting and disseminating findings. Consider:

- What: What is the story that you are trying to tell? What do you want to show or what is the question that you are aiming to answer or approach with this research?

- Who: Who is your audience? Who will you show these findings to?

- When: Are you looking at an ongoing problem or a specific point in time?

- How: How will you present this information and research? Report? On your website? At a public hearing? At a community meeting?
+ Develop Engagement Strategy for Action

+ Determine how you want to engage community members, CBOs, elected officials, etc. strategies may be different for each group

+ Conduct interviews with residents to confirm or "ground-truth" data

+ Presentation of findings to staff and community members to gather support for advocacy

The toolkits in the Community Research Lab toolbox provide useful concepts, instructions, and tips for implementing many of these steps. The Community Research toolkit can help you develop Steps 1, 3, 4, and 5 of this process, including how to create and conceptualize a research question. The Participatory Asset Mapping toolkit can guide you in developing Steps 3-5, including how to facilitate community-engaged mapping to collect data from community members.

HOW CAN YOU BEGIN TO ANSWER SOME OF THESE QUESTIONS FOR YOUR PROJECT? 


\section{Glossary}

\section{Administrative Data}

Data collected by persons, organizations or departments of government for their own purposes but often made available for public use and research.

\section{Applied Research}

Research typically designed by professional researchers for the purpose of addressing a particular issue or concern.

\section{Asset}

The status, condition, behavior, knowledge, or skill that a person, group, or an entity possesses and which serves as a support, resource, or source of strength to one's self and others in the community.

Individual assets are assets which can also be referred to as gifts of individuals, such as skills, training, education, specific talents, networks, and monetary resources.

\section{Community assets are comprised of:}

- Citizen Associations, which can include informal and formal institutions found within a community, such as social groups, recreation programs, churches, and block clubs.

- Local Institutions, which include institutions that reach into the community, such as businesses that create local job opportunities, social service agencies, health services (hospitals and clinics), libraries, schools (children and adult schools), colleges or universities.

\section{Boundary}

The geographic limits of a region of interest, which may include an entire study region or smaller areas representing units of analysis.

\section{Community}

A group of people living in the same locality, a group of people sharing common interests or similar identity, or the district or locality in which such groups live.

\section{Community Based Participatory Action} Research (CBPAR)

A framework for research that aims to address the practical concerns of people in a community. CBPAR is a collaborative approach to research that involves all stakeholders throughout the research process, from establishing the research question, to developing data collection tools, to analysis and dissemination of findings.

\section{Community-Based Research (CBR)}

A collaborative research model that is based on the notion that communities and researchers can have common or complementary goals and can combine their assets to conduct research that the community uses to create social change. ${ }^{\text {vi }}$ The audience for such findings is typically made up of community members, practitioners, and local policymakers who wish to design an intervention that benefits a geography- or population-based community. vii

\section{Community-Engaged Mapping}

A group mapping exercise designed to answer specific research questions and gather neighborhood-level primary data from community members (who live, work or attend school in the area), for the purpose of developing place-based planning, policy, and interventions.

\section{Data}

Measurements of any characteristics of interest. Ex: How many children live here? How do teenagers feel about homework? What type of detergent is most popular among grocery store shoppers? How many liquor stores are there in my neighborhood?

\section{Focus Groups}

A primary data collection method that involves interviewing participants in a group generally composed of no more than 10 people who were selected because they share certain characteristics relevant to the purpose of the research. For example, if your research question focuses on the quality of food in the community, your focus group may include residents (parents, children, business owners) who live locally and regularly depend on the food outlets in your community of interest. 


\section{Glossary}

\section{Geographies}

Spatial (non-physical) boundaries (also, units) for which data is collected. On the HealthyCity.org site, these are shapes that represent boundaries, usually established by socio-political decisions, for which secondary or administrative data is collected. Here are just a few common geographies.

Census tract - A census tract is a small, relatively permanent statistical subdivision of a county delineated by a local committee of census data users for the purpose of presenting data. Census tract boundaries normally follow visible features, but may follow governmental unit boundaries and other non-visible features in some instances; they always nest within counties. Designed to be relatively homogeneous units with respect to population characteristics, economic status, and living conditions at the time of establishment, census tracts average about 4,000 inhabitants. They may be split by any sub-county geographic entity.

Block group - A block group is a subdivision of a census tract (or, prior to 2000, a block numbering area). It is the smallest geographic unit for which the Census Bureau tabulates data. A block group consists of all the blocks within a census tract, beginning with the same number. Block groups generally contain 600 - 3,000 people.

ZIP Code - A ZIP (Zone Improvement Plan) Code is a five-, seven-, nine-, or eleven-digit code assigned by the U.S. Postal Service to a section of a street, a collection of streets, an establishment, structure, or group of post office boxes, for the delivery of mail. The Census uses the ZIP Code Tabulation Area (ZCTA) instead of the ZIP Code for data. A ZIP Code Tabulation Area is a geographic area that approximates the delivery area for a 5-digit or a 3-digit ZIP Code. ZCTAs do not precisely depict the area within which mail deliveries associated with that ZIP Code occur.

\section{Geographic Information System (GIS)}

Geographic Information System (GIS) is a computer application used to store, view, and analyze geographical information, or information associated with a location. Typically, a GIS is used for creating and handling maps. GIS allows researchers to identify spatial (see term) patterns among problems and resources.

\section{Ground-truth}

The action of exploring the validity of data and information based on the account of community members. Pursuing on-the-ground knowledge to verify data claims; also, the process of checking data and maps against reality, which may involve checking the map against other data sources or traveling to the place where the data were collected.

\section{Interviews}

A primary data collection method which involves the use of open-ended questions aimed to obtain information specific to research needs in a one-on-one setting between a researcher and a participant.

\section{Multi-sectored}

Includes agency representation from more than one sector, such as schools, business, philanthropy, governmental agencies, law enforcement, faith based organizations, neighborhood associations and other forms of private, public and/or quasi public/private agencies.

\section{Neighborhood}

A district or area with distinctive characteristics, or the physical space of a localized area.

\section{Participatory Action Research (PAR), or Action Research}

A research approach that emphasizes strong collaboration between the researcher and community residents on all aspects of research design. Participatory Action Research engages people in improving their experiences, particularly in organizational settings. ${ }^{\text {viii It does }}$ not, however, change the setting itself, the structure of the organization, or individuals' power within the organization.

\section{Place}

An area with definite or indefinite boundaries; a locality.

Place-Based

Focused on a specific place or locality. 


\section{Glossary}

\section{Primary Data}

Original data collected by the researcher specifically for the purpose in mind. For example, collecting student perceptions on school safety through a survey or interview with the students.

\section{Research Ethics}

The principles and rules that guide how people should be treated, when they are participants in a research process or project.

\section{Stakeholder}

A person or group that has an investment, share, or interest in an entity, such as a business, community or organization.

\section{Surveys}

Tools used for collecting all types of data, which usually involve participants completing a written questionnaire, sometimes administered in-person, over the telephone, or through an electronic survey system. 


\section{Resources}

All of the resources below contain free information, guides, and toolkits available to be downloaded, saved, and/or printed.

+ Community Research Lab Toolbox- Healthy City: A non-profit/non-university based resource containing guides and toolkits that combines mapping technology, best practices from research with community-based organizations, and the CBPAR framework described in this guide. http://www.healthycity.org/toolbox

+ The Community Toolbox- Work Group for Community Health and Development (University of Kansas): Offers more than 7,000 pages of practical, step-by-step guidance in creating change and improvement and building healthy communities. http://ctb.ku.edu

+ Participatory Action Research (PAR) ToolkitOregon Institute on Disability and Development (Oregon Health \& Science University): Contains modules, which include guides and PowerPoint presentations, for conducting Participatory Action Research. http://www.ohsu.edu/oidd/ partoolkit

+ A Manual for Community Based Participatory Research (CBPR): An extensive guide on all stages of a CBPR project. http://www. shepscenter.unc.edu/research_programs/ aging/publications/CEAL-UNC\%20Manual\%20 for\%20Community-Based\%20Participatory\%20 Research-1.pdf

+ Community-Based Participatory ResearchCommunity-Campus Partnerships for Health (University of Washington): Contains resources from a network of over 2,000 communities and campuses across North America that are collaborating to promote health through service-learning community-based participatory research, broad-based coalitions and other partnership strategies. http://www.ccph.info

\section{References}

i. National Institutes of Health. (2010). CommunityBased Participatory Research. Retrieved from http://obssr.od.nih.gov/scientific_areas/ methodology/community_based_participatory_ research/index.aspx

ii. Strand, K., Marullo, S., Cutforth, N., Stoecker, R., \& Donohoe, P. (2004). Community-based Research and Higher education: Principles and Practices. Kerry Strand, Sam Marullo, Nick Cutforth, Randy Stoecker and Patrick Donohoe. San Francisco: Jossey-Bass.

iii. Chun-Chung, Chow \& Crowe, Kelsey. (2005). Community-Based Research and Methods in Community Practice. In Marie Weil (Ed.), The Handbook of Community Practice (pp.604-619). Thousand Oaks: Sage Publications, Inc.

iv. Chun-Chung, Chow \& Crowe, Kelsey. (2005). Community-Based Research and Methods in Community Practice. In Marie Weil (Ed.), The Handbook of Community Practice (pp.604-619). Thousand Oaks: Sage Publications, Inc.

V. Israel, B.A., Schultz, A.J., Parker, E.A., Becker, A.B., Allen III, A.J., \& Guzman, J.R. (2000). Critical Issues in developing and following CBPR principles. In Meredith Minkler and Nina Wallerstein (Eds.), Community-Based Participatory Research in Health (pp. 47-66). San Francisco: Jossey-Bass.

vi. Strand, K., Marullo, S., Cutforth, N., Stoecker, R., \& Donohue, P. (2003). Community-based research and higher education: Principles and practices. San Francisco, CA: Jossey-Bass.

vii. Chun-Chung Chow, \& Crowe, Kelsey. (2005). Community-Based Research and Methods in Community Practice. In Marie Weil (Ed.), The Handbook of Community Practice (pp.604-619). Thousand Oaks: Sage Publications, Inc.

viii. Stoecker, Randy. (2005). The Goose Approach to Research. In Research Methods for Community Change. (pp. 27- 58).Thousand Oaks: Sage Publications, Inc. 


\section{Advancement Project - Healthy City}

1910 West Sunset Blvd. Suite 500

Los Angeles, CA 90026

(213) 989-1300

www.advancementprojectca.org

www.healthycity.org

ADVANCEMENT

PROJECT

HealthyCity 